\title{
KNOWLEDGE MANAGEMENT TECHNOLOGY FOR DECISION SUPPORT: AN EMPIRICAL EXAMINATION
}

\author{
Meliha Handzic \\ School of Information Systems. Technology and Management \\ The University of New South Wales \\ Sydney 2052, Australia \\ Phone: (02) 93854935 \\ Fax: (02) 96624061 \\ E-mail: m.handzic@unsw.edu.au
}

\begin{abstract}
This paper reports the results of an empirical examination of the effectiveness of one type of knowledge management technology, namely 'contextual knowledge repository', for supporting individual decision makers in a predictive judgement task context. 31 volunteer subjects participated in the study. The results indicate that a given technology was fairly useful, but insufficient to maximally enhance individual decision making. On one hand, subjects were found to extract more knowledge and make significantly smaller decision errors than their notional naive counterparts. On the other hand, subjects tended to extract less knowledge and make significantly larger decision errors compared to notional optimal counterparts. These findings suggest that individuals could potentially benefit from those knowledge management technologies that would provide additional explicit analytical and procedural knowledge, or those that would facilitate sharing of tacit knowledge through interaction with others. Future research is necessary to address these issues.
\end{abstract}

\section{INTRODUCTION}

Human society is experiencing a major transformation from an industry-based society to a knowledge-based society. With this transition, there is a growing recognition among researchers and practitioners alike for the need to better understand the value of knowledge, what knowledge is, and how it should be managed. In general, knowledge management literature indicates a widespread recognition of the importance of knowledge with respect to the struggle for economic success (Devlin, 1999; Drucker, 1993; Stewart, 1997), but little shared understanding of the construct itself (Davenport and Prusak, 1998; Devlin, 1999; Grayson and Dell, 1998). There are also differences among researchers in what constitutes useful knowledge and the ways in which it is created. Some theorists show more interest in codified repositories and information processing as enablers of 'explicit' objective and systematic knowledge (Baxter and Chua, 1999). Others focus more on 'tacit' knowledge that people derive from their experiences and from social interaction with others (Nonaka and Takeuchi, 1995; Nonaka, 1998).

As organisations become more knowledge-based, their success increasingly depends on how successful knowledge workers are at creating and applying new ideas productively and efficiently. The central task of those concerned with knowledge management is to determine ways to better cultivate, nurture and exploit knowledge at individual, group and organisational levels. A generic model of knowledge management (AA, 1998) suggests four organisational initiatives - leadership, culture, technology and measurement - as major enablers that facilitate knowledge management processes and foster the development of new knowledge. However, given the current infancy of the knowledge management research, there is little empirical evidence regarding the actual impact of these initiatives on knowledge processes and returns from their application. The main purpose of this paper is to provide a deeper insight into the impact of one particular technology initiative - codified knowledge repository - on individual working knowledge and performance in the context of decision making.

Codified knowledge repositories fall into the category of knowledge management systems for managing knowledge artifacts that have an inherent structure (eg. sales figures in a data warehousing system) or those where the system imposes a structure on the contents (eg. keyword tagged report in a document repository). Typically, these systems use database management systems and capture enterprise wide data from the organisational knowledge domain (Hahn and Subramani, 2000). It is implicitly assumed that the availability of such systems should lead to an increase in individual working knowledge and result in better job performance. This study intends to empirically test this assumption.

Various knowledge management systems implementations provide differing levels of support in locating and extracting knowledge and impose differing burdens to their users. The main objective of the current study is to determine the nature of assistance, the extent of assistance and the limitations of codified knowledge repositories in supporting knowledge work of managerial decision makers. In particular, this study examines whether and how explicit contextual knowledge that is captured in computerised stores may assist individual decision makers in enhancing 


\section{AJIS Special Edition}

Knowledge Management

December 2001

their working knowledge and improve the quality of their subsequent decisions in a specific judgemental decision making task.

\section{LITERATURE REVIEW AND RESEARCH QUESTIONS}

\section{Contextual Knowledge and Decision Making}

Theoretically, the availability of environment and organisation specific knowledge, as well as a variety of causeeffect relationships, can play an important role in improving decision quality. The value of such contextual knowledge may be seen primarily in its ability to explain past and anticipate future changes in the behaviour of any particular variable of interest and enabling the decision maker to deal more competently with his or her decision task. In the case of production planning, for example, product and industry knowledge should help the decision maker to make more accurate estimates of future sales, translate them into more suitable production plans and, as a result, minimise losses due to overproduction or missed sales opportunities. This suggests that the provision of valid contextual knowledge in codified organisational databases should increase the decision maker's working knowledge base and consequently improve an individual's decision performance.

Past empirical studies indicate mixed and inconclusive findings. Several studies using real world settings support the notion that contextual knowledge improves the quality of human judgement. Edmundson et al. (1988) found that business practitioners who possessed considerable knowledge of the specific products being forecast made more accurate sales predictions than students with no such contextual knowledge. This finding was also supported by Sanders and Ritzman (1992). Comparative analysis showed that the difference in the accuracy of forecasts generated with and without contextual knowledge was particularly significant under conditions of high variability of time series data. In addition, human judgement with contextual knowledge was found to lead to improved forecast accuracy over statistical models (Edmundson et al., 1988; Fildes, 1991). In the judgemental adjustment context, non-time series contextual knowledge was also found to be beneficial. Mathews and Diamantopoulos $(1986,1989)$ reported that managers who possessed considerable product knowledge were able to successfully adjust exponential smoothing forecasts. Similarly, Wolfe and Flores (1990) showed that the accuracy of a statistical forecast could be improved when judgementally adjusted in the light of contextual knowledge when the statistical forecast was of low-quality and the time series involved contained a high level of variability.

In contrast, a more recent field study of sales forecasting by Lawrence et al. (1995) revealed that bias and inefficiency could mask any contribution of seemingly helpful contextual knowledge to the accuracy of judgemental forecasts. This study compared the accuracy of judgementally produced monthly product forecasts with naive forecasts of thirteen companies. Contrary to expectations, the company forecasts were more accurate than the naive forecasts in only four of the companies, while the naive forecast was more accurate than the company forecasts in two companies. In the remaining seven companies, the difference was insignificant.

Empirical evidence from a number of laboratory studies also casts doubt on people's ability to effectively process explicit contextual/causal knowledge. In a study comparing the accuracy of judgemental causal forecasting with judgemental extrapolation, Andreassen (1991) showed that the causal group, provided with current situational diagnostic variables, significantly underperformed the extrapolation group. Similarly, Harvey et al. (1994) found that cross-series forecasts of train passengers made from correlated train criminals series were less accurate than the corresponding within-series forecasts made from the past passengers series only. However, it is possible that these causal variables had poor predictive validity. Finally, in a series of judgemental adjustment studies, Lim and O'Connor $(1995,1996$ a) found that people had difficulty in placing adequate weight on the reliable causal factors and did not learn to modify this behaviour over time. When the environment was multivariate, people were found to have problems in both evaluating and using the explicit contextual knowledge available (Lim and O'Connor, 1996b). Task complexity may be one of the potential contributing factors to the reported inefficiency (Beach and Mitchell, 1978; Payne, 1982; Wood, 1986).

\section{Research Questions}

In view of inconsistent prior findings and concerns expressed, it is of particular interest to this study to examine the situation in which decision makers are provided with a small amount (to avoid complexity) of highly predictive contextual knowledge (to ensure validity) in regard to the decision response. It is argued that such a situation well represents a typical context of a real world organisation in which its critical knowledge is packaged for use in a 'knowledge mart'. The question is (i) whether and how well can individual decision makers make sense of what is available 
in such knowledge repositories and enhance their working knowledge, and (ii) whether and what impact the application of that knowledge may have on their subsequent decision performance.

\section{RESEARCH METHODOLOGY}

\section{Experimental Task}

The experimental task for the current study was a simple production planning activity in which subjects made decisions regarding daily production of fresh ice-cream. The participants assumed the role of Production Manager for an imaginary dairy firm that sold ice-cream from its outlet at Bondi Beach in Sydney, Australia. The company incurred equally costly losses if production was set too low (due to loss of market to the competition) or too high (by spoilage of unsold product). The participants' goal was to minimise the costs incurred by incorrect production decisions. During the experiment, participants were asked at the end of each day to set production quotas for ice-cream to be sold the following day. Subjects were required to make thirty production decisions over a period of thirty consecutive simulated days. Before commencing the task, participants had an opportunity to make five trial decisions (for practice purposes only).

Ice-cream was demanded by consumers whose decision to buy or not was based on a number of determinants. From pre-experiment discussions with actual store owners at Bondi Beach, three factors emerged as important in determining local demand for product: the ambient air temperature, the amount of sunshine and the number of visitors/tourists at the beach. This important contextual knowledge was provided to the participants in addition to past product demand to aid their decision making. Subjects were free to access and use the available knowledge as they wished to. During the experiment, each subject was required to indicate his or her subjective assessment of the value of the available knowledge, and dominant strategy used in making production decisions. Contextual time series were artificially generated with cue-criterion correlations set to $r=0.65$ to ensure high predictive power. Optimal decision rule was derived by using a linear regression model with three contextual factors as independent and product demand as dependent variables in the equation.

The task was challenging. The participants were provided with the meaningful task context, a history of task relevant variables to provide some clues to causal relationship, and forecast values of the three contextual variables to suggest future behaviour. However, they were not given any explicit analysis of the predictive quality of their factors, or optimal rule they could apply to make specific judgements. At the beginning of the experiment, task descriptions were provided to inform subjects about the task scenario and requirements. In addition, throughout the experiment, instructions and feedback were provided to each participant to analyse earlier performance and to adjust future strategies.

\section{Experimental Design and Variables}

The experimental design for the study was a single factor design with experimental subject as the only independent variable. Experimental subjects were divided into three groups. The first group consisted of actual student subjects. The other two groups consisted of their nominal naive and optimal counterparts. These were imaginary decision makers who produced their decisions by using naive (random walk) and optimal (linear) strategies respectively.

Subjects' performance was evaluated in terms of decision accuracy and subjective assessments of decision process. Decision accuracy was operationalised by absolute error (Makridakis, 1993) and calculated as the absolute difference between subject-estimated and actually-demanded units of product per day. In addition, the corresponding errors of nominal naive and nominal optimal decision makers were calculated. These scores were used to assess how much of the available contextual knowledge was used by the actual subjects in making their decisions. Subjective assessments included perceived value of contextual knowledge and self-reported dominant decision strategy applied on the task. This information was collected to supplement the measure of decision accuracy, which was the primary indicator of the successful knowledge enhancement and application.

\section{Subjects and Procedure}

The real subjects were 31 graduate students enrolled in the Master of Commerce course at The University of New South Wales, Sydney. They participated in the experiment on a voluntary basis, had no prior knowledge of the task and received no monetary incentives for their performance. Generally, graduate students are considered to be appropriate subjects for this type of research (Ashton and Kramer, 1980; Remus, 1996; Whitecotton, 1996). The experiment was conducted in a microcomputer laboratory. On arrival, subjects were given a diskette with an appropriate 
version of the research instrument to be used. The instrument was specifically developed by the author in Visual Basic. Subjects were briefed about the purpose of the study, read case descriptions and performed the task. The session lasted about one hour.

\section{RESULTS}

\section{Decision Accuracy}

The collected data were analysed statistically using a series of t-tests to compare actual subjects' decision accuracy with that of their nominal naive and optimal counterparts. Results are presented graphically in Figure 1.

The analysis performed found a significant difference in mean absolute error scores (MAE) between actual subjects and nominal naive decision makers ( 429 vs $502, t=-4.45, d f=929, \mathrm{p}=0.000$ ). As shown in Figure 1, actual subjects tended to make smaller decision errors than their nominal naive counterparts. Further analysis showed that they achieved $14.5 \%$ reduction in decision error due to the acquired contextual knowledge.

The results of the analysis also revealed a significant difference in mean error scores (MAE) between actual subjects and nominal optimal decision makers ( 429 vs $203, t=15.78, d f=929, p=0.000$ ). Figure 1 shows that actual subjects

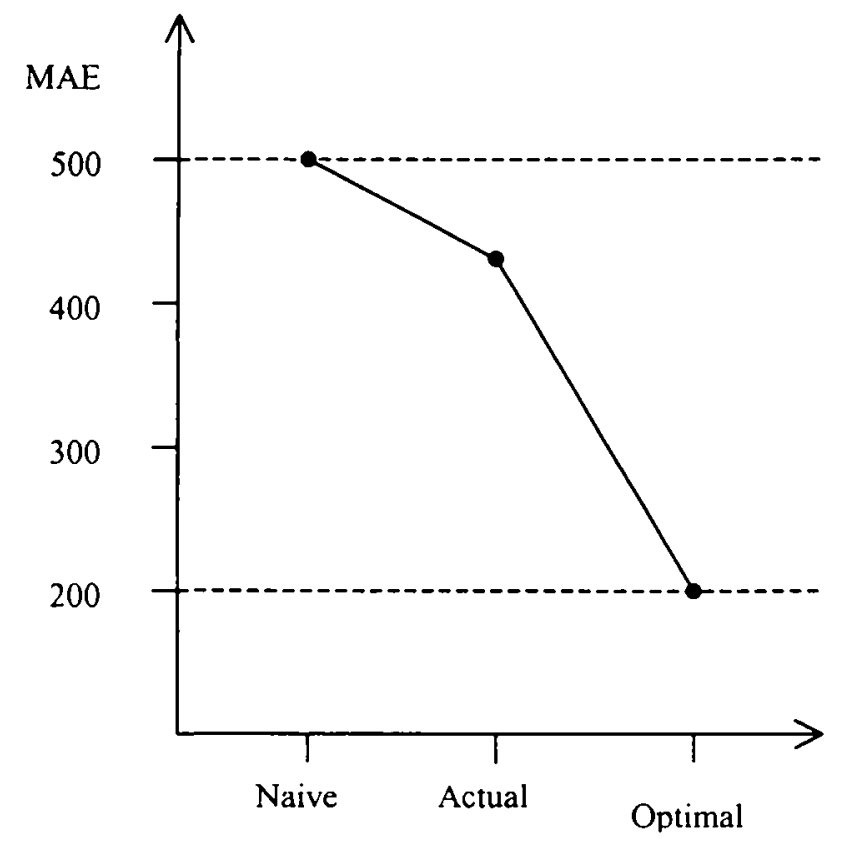

Figure 1. Decision Performance (MAE)

by Experimental Subjects

tended to make greater decision errors than their simulated counterparts applying an optimal linear strategy. Further analysis found that they tended to use effectively only $24.4 \%$ of the available contextual knowledge from the given repository.

\section{Subjective Assessments}

The analysis of the participants' subjective responses to a questionnaire indicated that most of them perceived the available knowledge as valuable, but misinterpreted the relative importance of individual contextual factors. Only $9.7 \%$ of the subjects accurately discovered that "all three factors are equally important in predicting sales". A majority of $64.5 \%$ assessed "all three contextual factors are important, but some more than others", while $16.1 \%$ found "two out of three contextual factors are relevant". The remaining $9.7 \%$ had various other interpretations. 
With respect to self-reported dominant strategies, the analysis indicated that these were largely consistent with earlier reported subjective assessments. Only $12.9 \%$ of the subjects applied normatively optimal "equal weighting" judgement strategies. A majority of $54.8 \%$ applied "differential weighting" linear models, while $16.1 \%$ "followed the direction of two factors in agreement". The remaining $16.2 \%$ applied various other mixed strategies.

\section{DISCUSSION}

\section{Main Findings}

In summary, the main findings of this study indicate that valid contextual knowledge embedded in computerised repositories enhanced individual decision makers' performance, however performance gains were less than theoretically possible. This was demonstrated by significantly smaller decision errors found among actual subjects than their notional naive counterparts, but greater decision errors compared to notional optimal counterparts.

The fact that participants performed better than naive decision makers indicates that they were able to discover and use some of the available contextual knowledge from their repositories. The analysis found that most subjects tended to identify as relevant and use at least two (out of three) contextual cues in making their decisions. As a result, they tended to achieve some improvement in their subsequent performance. In real terms, decision errors dropped by $14.5 \%$. Such findings seem to contradict the overly pessimistic picture of human ability to utilise contextual knowledge painted by earlier laboratory research in judgement and decision making (see eg. Andreassen, 1991; Harvey et al. 1994).

One potential explanation for the difference may be in the characteristics of the decision tasks. Participants in the current study were provided with a meaningful task context, a small number of highly predictive contextual variables, their historic time series to provide some clues to causal relationships, and forecast values to suggest future behaviour. It is also possible that a graphical form of presentation facilitated interpretation and enabled the subjects to better judge the right direction of future changes. This is consistent with Lawrence et al. (1985) findings that graphical presentation enhances the accuracy of novice decision makers.

Despite this, the results indicate a lot of room for further improvement. Actual subjects were found to make substantially greater decision errors than their nominal optimal counterparts. Greater than optimal errors indicate that the subjects tended to uncover and use much less of the available knowledge than they possibly could. Further analysis revealed that, on average, they tended to effectively internalise only $24.4 \%$ of the explicit knowledge provided to them. The failure to achieve optimal performance resulted mainly from the participants' misinterpretation of relative importance of individual contextual factors, and subsequent choice and application of inappropriate judgement strategy.

A potential explanation for the observed suboptimality may be the lack of vital analytical and procedural knowledge in their repositories. Subjects in the current research were not given any explicit analysis of the quality of their contextual factors, or rules they could apply to integrate the available factual knowledge into single decision response. Instead, all subjects had an opportunity to learn from own experience through task repetition and from feedback. However, it seems that the period of thirty trials was too short to induce more effective learning. Earlier studies on learning from feedback in multivariate tasks (for review see Klayman, 1988) indicate that while people can reasonably well learn the existence and direction of cue-criterion relations over a number of trials, they generally have difficulty in learning their shape. As a result they tend to perform sub-optimally.

In summary, the main findings of the present study indicate that the provision of a knowledge repository containing task relevant contextual knowledge was useful in improving decision making, but insufficient to enable individual decision makers to achieve optimal performance.

\section{Limitations}

While the current study provides a number of interesting findings, some caution is necessary regarding their generalisability due to a number of limiting aspects. One of the limitations refers to the use of a laboratory experiment that may compromise external validity of research. Another limitation relates to artificial generation of information that may not reflect the true nature of real business. The subjects chosen for the study were students and not real life decision makers. The fact that they were mature graduates may mitigate the potential differences. No incentives were offered to the subjects for their effort in the study. Consequently, they may have found the study tiring and unimportant and not tried as hard as possible. Most decisions in real business settings have significant consequences. Further research is necessary that would extend the study to other subjects and environmental conditions in order to ensure the generalisability of the present findings. 
AJIS Special Edition

Knowledge Management
December 2001

\section{Practical Implications and Directions for Future Research}

Although limited, the findings of the current study may have some important implications for organisational knowledge management strategies. They suggest that decision makers could potentially benefit from additional knowledge management initiatives that would enhance their understanding of the value of explicit knowledge embedded in organisational repositories. One possible solution is to provide repositories with more meaningful analysis, procedural knowledge and learning histories that might potentially help such workers better understand what works when and why (Kleiner and Roth, 1998). This, in turn, may result in better performance. Alternatively, organisations may employ specialists trained in analytical and statistical reasoning who would perform a knowledge filtering process for professional and managerial knowledge workers (Godbout, 1999).

Initiatives aimed at creating working contexts that encourage communication and culture of knowledge sharing may also potentially have a beneficial effect on enhancing decision makers' working knowledge and performance. Organisations have come to realise that a large proportion of the knowledge needed by the business is not captured on hard drives or contained in filing cabinets, but kept in the heads of people. Sources report that between $40 \%$ (AAOTE, 1998) and 90\% (Hewson, 1999) of the needed knowledge is (in the lingo of the business) tacit. The spiral knowledge model postulates that the processes of sharing will result in the amplification and exponential growth of working knowledge (Nonaka and Takeuchi, 1995; Nonaka, 1998). Yet, little is known of the ways in which tacit knowledge is actually shared, conditions under which this sharing occurs, and the impact it has on performance.

Finally, by combining and integrating various knowledge management initiatives organisations may potentially create synergy effects that would lead to even higher levels of knowledge and performance. According to Davenport and Prusak (1997) only by taking a holistic approach to management, it may be possible to realise the full power of knowledge ecology. Further research may look at some of these initiatives and approaches.

\section{CONCLUSIONS}

The main objective of this study was to investigate the impact of contextual knowledge repositories on individual decision makers' performance in the specific predictive judgement task. The findings indicate that participants were able to uncover and use some, but not all, relevant knowledge embedded in their available repositories. Accordingly, they achieved some performance improvement, but failed to fully accomplish what was possible. Although limited to the specific task and context, these findings may have important implications for organisations, as they suggest the need for implementing additional knowledge management initiatives to further enhance individual knowledge and performance. Therefore, more research is necessary to systematically address various initiatives in different tasks and contexts, and among different knowledge workers, if a better understanding of the area is to be achieved.

\section{REFERENCES}

AA (1998) The Knowledge Management Practices Book, The Global Best Practices Research Team, Arthur Andersen, January.

AAOTE (1998) BC Knowledge Management, Arthur Andersen Office of Training and Education, Arthur Andersen.

Andreassen, P. B. (1991) Causal prediction versus extrapolation: Effects on information source on judgemental forecasting accuracy, Working paper, MIT.

Ashton, R.H. and Kramer, S.S. (1980) "Students as Surrogates in Behavioural Accounting Research: Some Evidence", Journal of Accounting Research, Vol. 18(1), pp. 1-15.

Baxter, J. and Chua, W.F. (1999) "Now and the Future", Australian Accounting Review, Vol. 9(3), pp. 3-14.

Beach L.R. and Mitchell T.R. (1978) “A Contingency Model for the Selection of Decision Strategies", Academy of Management Review, July, pp. 439-449

Davenport, T.H. and Prusak, L. (1997) Information Ecology, Oxford University Press, Oxford.

Davenport, T.H. and Prusak, L. (1998) Working Knowledge, Harvard Business School Press, Boston.

Devlin, K. (1999) Infosense:Turning Information into Knowledge, W.H. Freeman and Company, New York

Drucker, P.F. (1993) Post-Capitalist Society, Harper Business, New York.

Edmundson, R.H., Lawrence, M.J. and O'Connor, M.J. (1988) "The Use of Non-Time Series Information in Sales Forecasting: A Case Study", Journal of Forecasting, Vol. 7(3), pp. 201. 
Fildes, R. (1991) "Efficient use of information in the formation of subjective industry forecasts", Journal of Forecasting, Vol. 10, pp. 597-617.

Godbout, A.J. (1999) "Filtering Knowledge: Changing Information into Knowledge Assets", Journal of Systemic Knowledge Management, January, pp. 1-9.

Grayson, C.J. and Dell, C.O. (1998) "Mining Your Hidden Resources", Across the Board, Vol. 35(4), pp. 23-28.

Hahn, J. and Subramani, M.R. (2000) "A Frameworkof Knowledge Management Systems: Issues and Challenges for Theory and Practice", Proceedings of ICIS'2000, Brisbane.

Harvey, N., Bolger, F. and McClelland, A. (1994) "On the nature of expectations", British Journal of Psychology, Vol. 85, pp. 203-229.

Hewson, D. (1999), "Start Talking and Get to Work", Business Life, November, pp. 72-76.

Klayman, J. (1988) "Learning from Experience", in Brehmer, B. and Joyce, C.R.B. (eds) Human Judgement. The SJT View, North-Holland, Amsterdam.

Kleiner, A. and Roth, G. (1998) “How to Make Experience Your Company's Best Teacher”, Harvard Business Review on Knowledge Management, Harvard Business School Press. Boston.

Lawrence, M., Edmundson, B. and O'Connor, M. (1985) An Examination of Accuracy of Judgemental Extrapolation of Time Series, International J. of Forecasting, 1, 25-35.

Lawrence, M., O'Connor, M. and Edmundson, B. (1995) A Field Study of Sales Forecasting: Its Accuracy, Bias and Efficiency, Working paper, School of Information Systems, The University of New South Wales, July.

Lim, J.S. and O'Connor, M. (1995) "Judgemental Adjustment of Initial Forecasts: Its Effectiveness and Biases", Journal of Behavioural Decision Making, Vol. 8, pp. 149-168.

Lim, J.S. and O'Connor, M.J. (1996a) “Judgemental Forecasting with Time Series and Causal Information", International Journal of Forecasting, Vol. 12, pp. 139-153.

Lim, J.S. and O'Connor, M.J. (1996b) “Judgemental Forecasting with Interactive Forecasting Support Systems”, Decision Support Systems, Vol. 16, pp. 339-357.

Makridakis, S. (1993) “Accuracy measures: theoretical and practical concerns", International Journal of Forecasting, Vol. 9, pp. 527-529.

Mathews, B.P. and Diamantopoulos, A. (1986) "Managerial Intervention in Forecasting: An Empirical Investigation of Forecasting Manipulation", International Journal of Research in Marketing, Vol. 3, pp. 3-10.

Mathews, B.P. and Diamantopoulos, A. (1989) "Judgemental revision of sales forecasts: A Longitudinal Extension", Journal of Forecasting, Vol. 8, pp. 129-140.

Nonaka, I. (1998) "The Knowledge-Creating Company", Harvard Business Review on Knowledge Management, Harvard Business School Press. Boston.

Nonaka, I. and Takeuchi, H. (1995) The Knowledge Creating Company: How Japanese Companies Create the Dynamics of Innovation. Oxford University Press, New York.

Payne, J.W. (1982) "Contingent Decision Behaviour", Psychological Bulletin, Vol. 92 (2), pp. $382-402$

Remus, W. (1996) “Will Behavioural Research on Managerial Decision Making Generalise to Managers?”, Managerial and Decision Economics, Vol. 17, pp. 93-101.

Sanders, N.R. and Ritzman, L.P. (1992) "The Need for Contextual and Technical Knowledge in Judgemental Forecasting”, Journal of Behavioural Decision Making, Vol. 5(1), pp. 39-52.

Stewart, T.A. (1997) Intellectual Capital: The New Wealth of Organisations, Doubleday, New York.

Whitecotton, S.M. (1996) "The Effects of Experience and a Decision Aid on the Slope, Scatter, and Bias of Earnings Forecasts", Organisational Behaviour and Human Decision Processes, Vol. 66(1), pp. 111-121.

Wolfe, C. and Flores, B. (1990) "Judgemental Adjustment of Earnings Forecasts", Journal of Forecasting, Vol. 9(4), pp. 389-405.

Wood, R.E. (1986) "Task Complexity: Definition of the Construct", Organisational Behaviour and Human Decision Processes, Vol. 37(1), pp. 60-82. 